\title{
Impactos da agricultura no meio-ambiente: Principais tendências e desafios (Parte 1)
}

\author{
Mauricio Vaz Lobo Bittencourt*
}

\begin{abstract}
RESUMO - Este artigo tenta enfatizar a importância das tendências e desafios dos impactos da agricultura sobre o ar e a água. Dentre os componentes poluidores do ar que devem ser monitorados temos o metano, óxido nitroso, óxido nítrico, amônia, e dióxido de carbono, sendo que estes gases podem contribuir para a mudança climática e para a eutrofização e acidificação. No caso da poluição da água, devemos considerar seriamente o esgotamento dos lençóis freáticos, alagamentos e salinização, poluição por fertilizantes e pesticidas e o manejo inadequado dos rebanhos. A experiência dos países desenvolvidos pode servir de alerta aos países em desenvolvimento no que diz respeito aos impactos agro-ambientais, pois estes adotam padrões de intensidade de uso bastante similares àqueles. Diversas medidas estão sendo tomadas e estudadas de caráter regulatório, econômico e técnico pelos países desenvolvidos e em desenvolvimento para frear o ritmo de expansão dos diversos tipos de degradação do ar e da água.
\end{abstract}

Palavras-chave: Agricultura. Impactos ambientais. Poluição. Tendências. Desafios.

A agricultura é tida como uma atividade de grande impacto ambiental, pois é a atividade que mais consome água e a que mais causa poluição com nitrato nas fontes de águas subterrâneas e superficiais, além de maior poluição com amônia. Adicionalmente, a agricultura contribui significativamente para a poluição das águas com fosfatos, emissão de gases como metano e óxido nitroso. (OCDE, 2001a; IPCC, 2001a).

No entanto, tanto a agricultura como a exploração florestal têm sido vistas como importantes no que diz respeito a algumas externalidades positivas nas questões ambientais, tais como armazenamento e purificação da água, sequestro de carbono, e a manutenção das paisagens rurais.

Mas é inegável que a intensificação na exploração agrícola e florestal tem contribuído para a poluição da água e do ar (NELSON; MAREIDA, 2001; MAREIDA; PINGALI, 2001), com reduções na produtividade devido à degradação da água e do solo (MURGAI; ALI; BYERLEE, 2001).

Importantes limitações são visíveis em recentes estimativas dos custos ambientais da agricultura em diversos países desenvolvidos (PRETTY et al, 2001). Segundo este estudo, nos

\footnotetext{
*Professor Adjunto do Departamento de Economia da UFPR. Endereço eletrônico: mbittencourt@ufpr.br.
} 
próximos 30 anos os países em desenvolvimento deveriam dar atenção à poluição do ar e aos custos causados por ela, os quais podem exceder os custos da poluição da água, degradação da terra, perda de biodiversidade. Nota-se que grande parte destes custos ambientais é conseqüência das mudanças climáticas e seus impactos, os quais são incertos.

Ou seja, os países em desenvolvimento estarão enfrentando os mesmos tipos de impactos agro-ambientais severos que os países desenvolvidos enfrentaram nos últimos 30 anos ou mais.

Muitos países em desenvolvimento já têm taxas de uso de pesticidas e fertilizantes acima dos níveis utilizados em países desenvolvidos e que causam estragos ambientais. Similarmente alguns países em desenvolvimento possuem rebanhos mais numerosos que países da Europa e América do Norte, que são sérias ameaças aos recursos hídricos (OECD, 2001a). Um dos argumentos é de que maiores prioridades devem ser dadas de modo a se reduzir o impacto da agricultura na poluição do ar e da água.

\section{PRINCIPAIS TENDÊNCIAS E DESAFIOS}

\subsection{POLUIÇÃO DO AR E MUDANÇA CLIMÁTICA}

De acordo com Pretty et al (2001), tem-se dado maior atenção recentemente aos custos econômicos causados pela agricultura na poluição do ar. A agricultura afeta a qualidade do ar e a atmosfera de quatro maneiras: produção de $\mathrm{CO}_{2}$ devido às queimadas; metano oriundo da produção de arroz e animais; óxido nitroso oriundo de fertilizantes e esterco; e amônia de esterco e urina.

A queima de biomassa quando da limpeza do solo para plantio emite várias substâncias poluentes para a atmosfera. Esta é uma prática bastante comum na agricultura tropical, seja para estimular o desenvolvimento de forragens para os rebanhos, seja para limpar o terreno para novos plantios, principalmente no caso do arroz, mas cuja poluição se estende para regiões além da origem das queimadas.

Algumas práticas poderiam ser adotadas para reduzir tais impactos. No caso do desmatamento, utiliza-se muito a queimada para eliminação da vegetação remanescente. A redução do desmatamento através do fogo já poderia reduzir o crescimento da poluição do ar. Outra alternativa seria a mudança de criação de rebanhos do sistema extensivo para o intensivo. Mudanças climáticas, por sua vez, podem aumentar a temperatura nas estações 
mais secas do ano, aumentando o risco de incêndios e contribuindo para aumentar a poluição pela queima de biomassa em algumas áreas (LAVOREL et al, 2001).

No caso de emissão de gases estufa, para alguns países a emissão destes gases pela agricultura representa importante parcela do total de emissões nacionais, apesar deste ser raramente o tipo de emissão dominante. Esta participação da emissão de gases pela agricultura pode crescer à medida que as emissões derivadas da produção industrial e de energia crescem menos rapidamente. Existe também a preocupação com outras fontes de emissão, como a de metano, ácido nitroso, e amônia, os quais, em alguns países podem representar cerca de $80 \%$ do total de emissões de gases estufa pela agricultura.

A conversão de florestas tropicais em áreas agricultáveis, a expansão da produção de arroz e de rebanhos, e o aumento no uso de fertilizantes nitrogenados, têm contribuído bastante para a emissão de gases estufa. De acordo com a tabela 1, maior atenção tem sido dada recentemente à emissão de metano e óxido nitroso, pois a agricultura tem sido responsável por mais da metade das emissões globais antropogênicas ${ }^{1}$ destes gases.

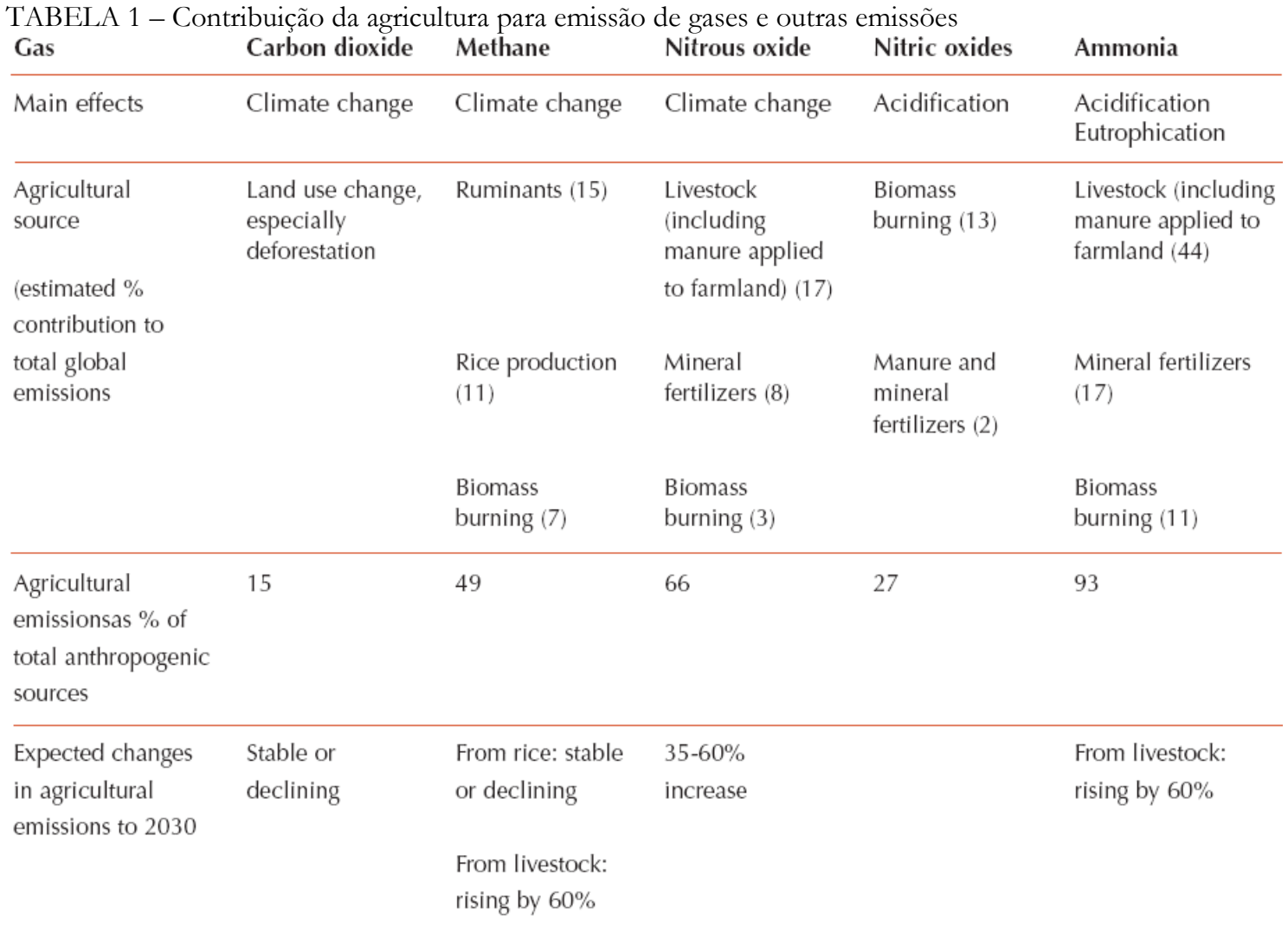

Main sources: Column 2: IPCC (2001a); column 3: Lassey, Lowe and Manning (2000); columns 4, 5 and 6: Bouwman (2001); FAO estimates.

${ }^{1}$ É aquela causada pela influência do homem. 
Metano é considerado o principal tipo de gás responsável por mudanças climáticas, pois seu potencial de aquecimento é 20 vezes maior que o do $\mathrm{CO}_{2}$, por absorver maior radiação infravermelha e ficar mais tempo na atmosfera. As emissões de metano na atmosfera vêm crescendo a taxa de 20 a 30 milhões de toneladas anualmente, sendo que a produção de arroz contribui em cerca de $11 \%$ e a produção animal com $15 \%$ do total de emissões globais de metano. A contribuição dos rebanhos varia de país para país e de acordo com o grau de intensidade. Na Inglaterra e no Canadá, por exemplo, esta contribuição chega a 35 \%.

O aumento nas emissões de metano pela produção animal em países em desenvolvimento tende a crescer à medida que aumenta a proporção de gado e produção de lácteos através de criações intensivas (confinamento), sendo que por volta de 2030 a maior parte da produção de suínos e aves ocorrerá em galpões próprios e em escala industrial, trazendo sérios riscos locais para o meio-ambiente.

As projeções futuras quanto à produção animal trazem aspectos positivos e negativos com relação à emissão de metano para o meio-ambiente. A maior produtividade, devido aos avanços nutricionais e à maior digestibilidade, devem reduzir as emissões de metano por animal. Por outro lado, o aumento no tamanho dos rebanhos e a mudança no sistema de criação extensiva em intensiva resultarão em maiores emissões de metano. A explicação para a mudança no sistema de criação se dá pelo armazenamento, quando do sistema intensivo, de esterco na forma líquida que é importante fonte de emissão de metano, principalmente em lagos ou tanques usados nas criações em confinamento. Quando se utiliza o metano para geração de energia tem-se alguns benefícios da mudança de sistema de criação. Se as emissões crescerem de forma direta com o tamanho dos rebanhos, as emissões de metano poderão ser até $60 \%$ maiores em 2030. Este crescimento deverá ser pequeno em países desenvolvidos, e bem maior nos países asiáticos, devido ao aumento dos rebanhos de suínos e aves.

O cultivo de arroz também contribui significativamente na emissão de gás metano. A área a ser colhida com arroz em 2030 é prevista como sendo 4,5\% maior, conforme Wassmann, Moya e Lantin (1998). Mas apesar deste aumento previsto, a emissão de metano pela produção de arroz poderá não aumentar muito podendo, inclusive, cair por duas razões. Primeiro, mais da metade da produção mundial de arroz se dá com contínuo alagamento, mantendo o solo em condições anaeróbicas, o que ocasiona maiores emissões de metano. Entretanto, devido ao aumento de falta de água, menor oferta de mão-de-obra, e maiores preços da água, é esperado que o arroz seja produzido cada vez mais sob irrigação controlada, 
com melhor gerenciamento dos nutrientes, o que deve contribuir para reduzir a emissão de metano. De acordo com Wang, Neue Samonte (1997), cerca de 90 \% da emissão de metano das plantações de arroz se dá pelas plantas de arroz, sendo que novas variedades que emitem menos metano já estão sendo disponibilizadas como alternativas às variedades tradicionais, o que poderá ser mais explorado no futuro.

O óxido nitroso é outra fonte de emissão de gás estufa, pela qual a agricultura é fonte antropogênica dominante. $\mathrm{O}$ uso de fertilizantes minerais e os rebanhos bovinos são os principais responsáveis pela emissão de óxido nitroso. Este é produzido por um processo biogênico natural, mas a produção é incrementada pela agricultura através do uso de fertilizantes nitrogenados, resíduos de colheitas, urina e fezes animais, e pela lixiviação de nitrogênio. A formação de $\mathrm{N}_{2} \mathrm{O}$ é sensível ao clima, tipo de solo, práticas de cultivo, tipo de fertilizante e maneira com que este é utilizado. A emissão de $\mathrm{N}_{2} \mathrm{O}$ também está associada à produção de ácido nítrico e amônia, que contribuem para a chuva ácida e acidificação dos solos e sistemas de drenagem (MOSIER; KROEZE, 1998).

A principal fonte de emissões de óxido nitroso é o fertilizante nitrogenado. De acordo com as projeções para 2030, poderá haver uma queda no crescimento da utilização de fertilizantes nitrogenados em torno de $37 \%$, contribuindo para reduzir as emissões de $\mathrm{N}_{2} \mathrm{O}$ e lixiviação de nitrogênio no solo. $O$ uso de fertilizantes nitrogenados em países em desenvolvimento costuma ser bastante ineficiente. Na China, por exemplo, que é o maior consumidor deste tipo de fertilizante, cerca de $50 \%$ de fertilizante é perdido por volatilização, e de 5 a $10 \%$ por lixiviação. Para reduzir tais perdas de nitrogênio são necessárias melhores práticas de manejo, incentivos econômicos para uso de fertilizantes balanceados e menores emissões de $\mathrm{N}_{2} \mathrm{O}$, e melhoramentos tecnológicos nas formulações para diminuir e retardar a perda de nitrogênio.

Os rebanhos são as principais fontes de emissões antropogênicas de óxido nitroso (MOSIER et al, 1996; BOUWMAN, 2001). Estas emissões ocorrem de três maneiras. Primeiro, pelo uso de compostagem em plantações e pastagens. Em países desenvolvidos, o uso de compostagem tem aumentado bastante, principalmente devido ao aumento na demanda por produtos orgânicos e melhor uso nutricional do solo. No caso de países em desenvolvimento, o oposto vem ocorrendo, com aumento no uso de fertilizantes minerais, principalmente pela queda na oferta de mão-de-obra e pela separação da produção animal de escala industrial das lavouras. Segundo, pelo depósito de fezes e urina dos animais no pasto. Segundo Mosier et al (1996), estas emissões são maiores em sistemas de criação mais 
intensivas do que no sistema extensivo. De modo similar, animais com alimentos de menor qualidade emitem menor quantidade de $\mathrm{N}_{2} \mathrm{O}$, que resulta em maiores emissões de $\mathrm{N}_{2} \mathrm{O}$ no futuro devido ao aumento na migração do sistema extensivo com menor qualidade de alimentos para o sistema intensivo com alimentos de maior qualidade. A terceira fonte vem do acúmulo de excrementos dos animais no sistema intensivo (confinado). De acordo com Mosier et al (1996), isto pode reduzir as emissões, pois o depósito de excrementos produz, em média, metade de $\mathrm{N}_{2} \mathrm{O}$ do que o exposto nas pastagens. As projeções apontam um aumento de 60\% na produção de compostagem até 2030. No entanto, as projeções para a emissão de $\mathrm{N}_{2} \mathrm{O}$ são de aumento de $50 \%$ devido ao maior uso do sistema intensivo de criação de animais.

No caso das emissões de amônia, a agricultura é a principal fonte de emissão antropogênica, a qual chega a ser cerca de quatro vezes maior que as emissões naturais. De acordo com Bouwman et al (1997) e Bouwman (2001) e tabela 1, a criação de bovinos responde por cerca de $44 \%$ das emissões globais, os fertilizantes minerais por $17 \%$, e queima de biomassa e restos de colheita por $11 \%$. A taxa de volatilização de fertilizantes minerais chega a ser 4 vezes maior nos países em desenvolvimento do que nos países desenvolvidos, devido às altas temperaturas e baixa qualidade dos fertilizantes usados naqueles.

De acordo com Galloway (1995), as emissões de amônia são potencialmente mais ácidas do que as emissões de óxido nitroso e dióxido sulfúrico. Apesar de ações serem feitas para a redução de dióxido sulfúrico pelas residências e pela indústria, e existir uma tendência de melhor uso de energia, existe pouco esforço na redução destas emissões pela agricultura. A amônia liberada de sistemas intensivos de criação animal contribui para depósitos de nitrogênio, causando problemas às florestas, acidificação e eutroficação dos sistemas aquáticos e terrestres, reduzindo a disponibilidade de nutrientes, redução da fixação de nitrogênio, e redução da biodiversidade (PITCAIRN et al, 1998; ASMAN, 1994).

Como a principal fonte de amônia são os excrementos dos rebanhos, e estes tendem a crescer à medida que se usa maior quantidade de concentrados, quanto maior o peso em carcaça, maior é a produção de amônia. Na tabela 2 podemos ver a diferença no aumento projetado de emissões de amônia entre os países em desenvolvimento e os desenvolvidos. $\mathrm{O}$ aumento de emissões para os países em desenvolvimento, projetado em cerca de 80 \%, é bem maior que o previsto por Bouwman et al (1997).

Estas projeções têm três implicações ambientais: 
(i) Todas as regiões em desenvolvimento apresentam níveis de emissão de amônia que têm causado muitos danos aos ecossistemas de países desenvolvidos;

(ii) Emissões devem continuar crescendo em países desenvolvidos, agravando ainda mais algumas áreas seriamente prejudicadas;

(iii) $\mathrm{Na}$ Ásia e América Latina uma maior proporção de emissões virá da criação de suínos, na qual a redução de emissões é mais difícil.

TABELA 2 - Projeções de emissões globais de amônia pela produção animal

\begin{tabular}{|c|c|c|c|c|}
\hline & \multicolumn{2}{|c|}{ Number of animals } & \multicolumn{2}{|c|}{ Emissions $\mathrm{NH}_{3}$} \\
\hline & $1997 / 99$ & 2030 & $1997 / 99$ & 2030 \\
\hline & \multicolumn{2}{|c|}{ (in millions) } & \multicolumn{2}{|c|}{ ('000 tonnes $\mathrm{N}$ p.a.) } \\
\hline & \multicolumn{4}{|c|}{ World } \\
\hline Total & & & 30.34 & 48.60 \\
\hline Cattle and buffalo & 1497 & 1858 & 13.09 & 19.51 \\
\hline Dairy & 278 & 391 & 5.35 & 9.98 \\
\hline Sheep and goats & 1749 & 2309 & 2.02 & 3.50 \\
\hline Pigs & 871 & 1062 & 6.62 & 9.25 \\
\hline \multirow[t]{2}{*}{ Poultry } & 15119 & 24804 & 3.27 & 6.35 \\
\hline & \multicolumn{4}{|c|}{ Developing countries } \\
\hline Total & & & 21.35 & 38.55 \\
\hline Cattle and buffalo & 1156 & 1522 & 9.33 & 15.34 \\
\hline Dairy & 198 & 312 & 3.63 & 8.08 \\
\hline Sheep and goats & 1323 & 1856 & 1.59 & 3.02 \\
\hline Pigs & 579 & 760 & 4.52 & 7.02 \\
\hline \multirow[t]{2}{*}{ Poultry } & 10587 & 19193 & 2.29 & 5.09 \\
\hline & \multicolumn{4}{|c|}{ Industrial countries } \\
\hline Total & & & 6.67 & 7.24 \\
\hline Cattle and buffalo & 254 & 243 & 3.03 & 3.18 \\
\hline Dairy & 41 & 44 & 1.02 & 1.21 \\
\hline Sheep and goats & 341 & 358 & 0.33 & 0.34 \\
\hline Pigs & 210 & 220 & 1.51 & 1.58 \\
\hline Poultry & 3612 & 4325 & 0.78 & 0.93 \\
\hline
\end{tabular}

FONTE: Mosier e Kroeze (1998).

\section{2 IMPACTO NA ÁGUA}

Muitos problemas relacionados ao uso inadequado da água e problemas de poluição da mesma vêm chamando a atenção de todos recentemente. Estaremos, agora, explorando mais atentamente alguns dos principais problemas relacionados ao uso e poluição da água pela agricultura.

\subsubsection{Esgotamento dos lençóis freáticos}

O esgotamento da água do subsolo vem sendo um problema global, pois tem ocorrido em países desenvolvidos e em desenvolvimento, e acontece quando o consumo de 
água excede a taxa natural de reposição da mesma. No norte e leste da África a água usada em irrigação vem de aqǘferos fósseis, que quase não tem reposição de forma sustentável (GLEICK, 1994). Em diversas áreas na China e Índia os níveis de lençóis freáticos vêm se reduzindo em cerca de 1-3 metros por ano. As conseqüências econômicas são cada vez maiores e os danos ao meio-ambiente são sérios e até irreversíveis. Excesso de uso destas águas em áreas costeiras pode fazer com a água salgada contamine os aqüíferos, tornando-os não adequados para irrigação e para consumo sem um tratamento com grandes dispêndios de recursos econômicos. Outra conseqüência econômica da redução dos lençóis freáticos é que à medida que os níveis de água baixam pelo uso excessivo da água, os custos de extração desta aumentam significativamente, o que pode inviabilizar alguns sistemas de irrigação no futuro.

\subsubsection{Alagamento e Salinização}

O problema de alagamento é, em geral, consequência do mau uso da irrigação, principalmente excesso de irrigação e drenagem inadequada. $\mathrm{O}$ alagamento acontece com a elevação dos níveis de água subterrânea, podendo preceder o processo de salinização, prejudicando o crescimento das plantas e a estrutura do solo. Cerca de 10 milhões de ha são afetados por alagamento no mundo (OLDEMAN; HAKKELING; SOMBROCK, 1991).

No caso da salinização, esta ocorre com o aumento do acúmulo de sólidos dissolvidos no solo e na água do solo, e pode ocorrer em áreas irrigadas e não irrigadas com solos bastante suscetíveis (como algumas partes da Austrália). A salinização é uma das principais causas de perda de solo. É possível que cerca de $20 \%$ da área total irrigada seja afetada pela salinização e cerca de 12 milhões de ha tenham deixados de ser usados devido a este problema em todo o mundo (NELSON; MAREIDA, 2001). O problema pode ser ainda mais sério a nível regional ou nacional. Em países do semi-árido, cerca de 10 a $25 \%$ das áreas irrigadas têm sido afetadas pela salinização (UMALI, 1993). Infelizmente não se tem séries temporais com informações destas perdas, pois é difícil a quantificação do problema.

\subsubsection{Poluição por fertilizantes}

O problema de lixiviação de nitrato do solo vem sendo problema na maior parte dos países industriais desde os anos 1970. Em vários países da Europa, por exemplo, as concentrações utilizadas são muito próximas de, ou até excedem, $50 \mathrm{mg}$ por litro ou 50 ppm. Este nitrato impõe um risco à saúde humana e contribui para a eutroficação de rios, lagos e 
águas costeiras. De acordo com Zhang et al (1996), este problema tem sido mais sério em partes da China e Índia e em alguns países em desenvolvimento. O problema ocorre quando o nitrogênio aplicado excede a capacidade das plantas em absorvê-lo, e esta quantidade depende do tipo de planta, solo e rochas presentes no solo, podendo variar bastante entre as regiões e países (GOULDING, 2000). Em partes da China a situação é bem complicada, pois alguns produtores de arroz aplicam cerca de $870 \mathrm{~kg} \mathrm{~N} /$ ha, quase quatro vezes acima da média nacional. Como podemos notar na tabela 3, na África acontece exatamente o contrário, pois os níveis utilizados de fertilizantes são extremamente baixos, com os níveis de fertilidade sendo baixos e declinantes.

Existem algumas observações a serem feitas: a) as perdas aqui salientadas podem ocorrer com taxas de aplicação de nitrogênio abaixo do ótimo econômico, pois os preços dos fertilizantes não incluem o custo das externalidades ambientais (PRETTY et al, 2001); b) maximização da eficiência no uso de nitrogênio é difícil e complexo (GOULDING, 2000); c) pode-se levar anos para se atingir um nível de eficiência no uso de nitrogênio de modo a se reduzir as perdas deste nutriente, e décadas para os lençóis freáticos se recuperarem da contaminação com nitrato; d) no caso da produção de vegetais, o problema é mais sério pela proximidade com áreas urbanas, correndo o risco de contaminação da água para consumo da população.

A contaminação da água com nitratos e fosfatos pode levar ao problema de eutroficação, resultando em alta mortalidade de peixes e aparecimento de algas, o que pode afetar a aquicultura, sendo que a presença de algas pode produzir toxinas que afetam peixes e humanos. Adicionalmente, o problema de acidificação do solo pode ser agravado com o mau uso dos fertilizantes aliado com a emissão de amônia por parte dos rebanhos.

\subsubsection{Poluição por pesticidas}

O uso de pesticidas vem aumentando bastante nos últimos 35 anos. Segundo Yudelman, Ratta e Nygaard (1998), o uso global de pesticidas vem aumentando a uma taxa de 4 a 5,4 \% por ano. A poluição pelo uso de pesticidas vem ocorrendo tanto em países desenvolvidos como em desenvolvimento. Mas o consumo de pesticidas pode aumentar mais nos países em desenvolvimento nos próximos anos (MORROD, 1995). No entanto, os impactos no meio-ambiente são de difícil mensuração. Por exemplo, as taxas de uso de pesticidas têm declinado, mas os pesticidas mais recentes são biologicamente mais ativos. 


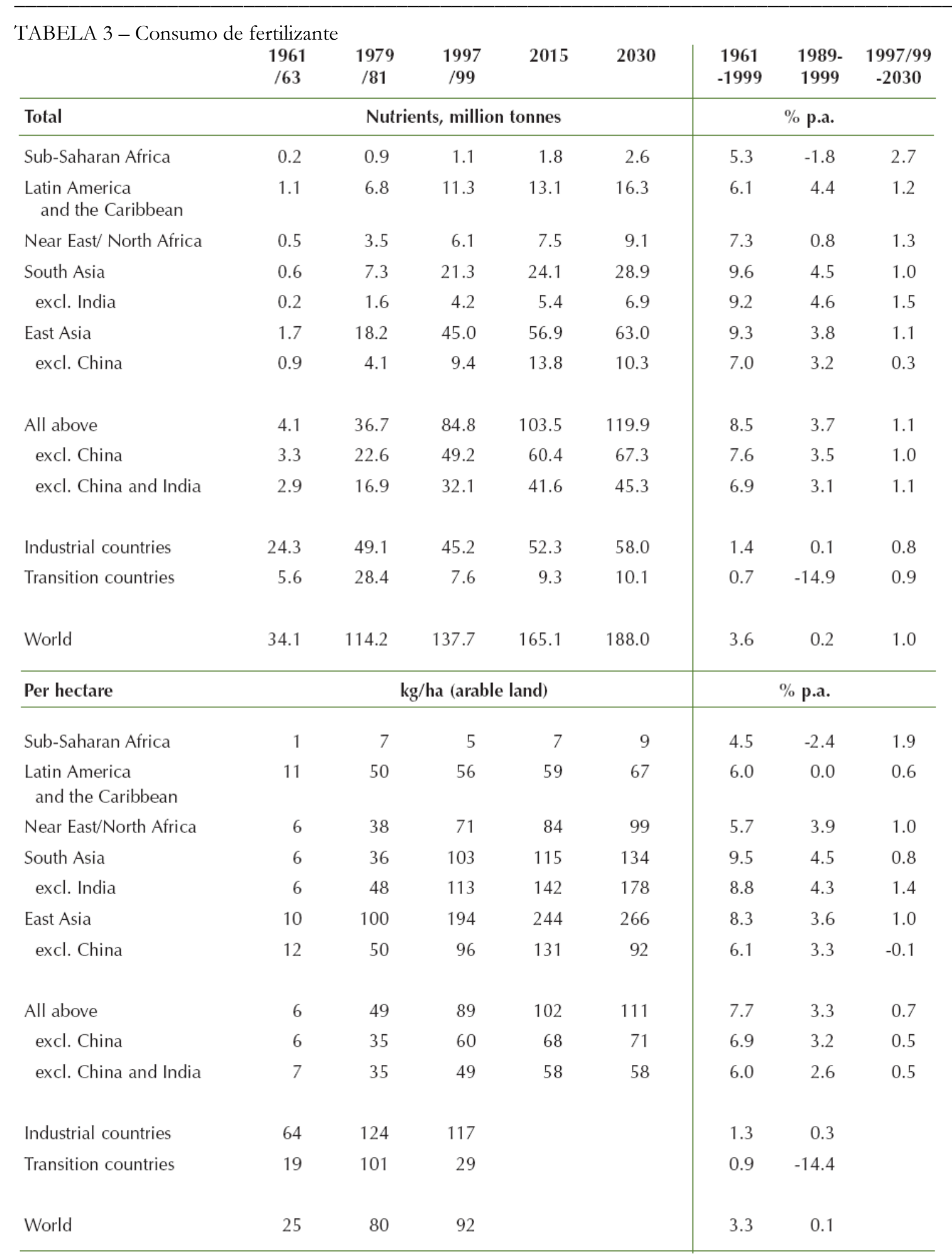

NOTA: Kg/ha para 1997/99 são para os países em desenvolvimento calculadas e ajustadas com base nos dados de área agricultável. Não foram feitas tais projeções para os países desenvolvidos e em transição. 
Países desenvolvidos estão adotando, cada vez mais, medidas regulatórias para o uso de pesticidas (DME, 1999), sendo que a maior demanda por alimentos orgânicos pode contribuir para a redução no uso de pesticidas, além de pesquisas e avanços com relação aos pesticidas "naturais" (THOMAS, 1998).

\subsubsection{Poluição causada pelo manejo dos rebanhos}

A poluição dos mananciais pode também ocorrer como conseqüência do manejo dos rebanhos, principalmente de suínos e aves, particularmente na Ásia ocidental onde vem causando sérios impactos no meio-ambiente, especialmente poluição de rios, sem precedente nos países industrializados. O problema aparece quando há manejo inadequado de nitrogênio e outros nutrientes oriundos dos dejetos dos animais em águas superficiais.

\section{CONSIDERAÇÕES FINAIS}

Países europeus e os Estados Unidos têm feito muitas pesquisas e adotado várias ações regulatórias para limitar a poluição por uso de fertilizantes, tais como: pesquisas para produção de fertilizantes menos poluentes e de menor velocidade de liberação de nutrientes; padrões de emissão de resíduos mais reduzidos para as fábricas, com severas multas; investimentos em serviços de extensão pública e privada; limites físicos no uso de compostagem e fertilizantes minerais; e aplicação de um orçamento de aplicação nutricional.

Alguns países deverão remover distorções como subsídios diretos e indiretos para a produção e vendas de fertilizantes minerais. Outras ações são o maior uso de técnicas como o plantio direto e maior demanda por parte dos consumidores de produtos orgânicos.

Rigorosos testes de pesticidas devem ser adotados antes que os mesmos entrem no mercado, tal que as informações de segurança destes produtos devem ser compartilhadas com outros países através do International Plant Protection Convention (IPPC), e de outros mecanismos. Os países em desenvolvimento devem implementar seus próprios procedimentos de teste, licença e controle. Uma última alternativa poderia ser a do uso de incentivos (ou desincentivos) para a redução no uso de pesticidas.

A água vem se tornando escassa com menor reposição de água nos mananciais subterrâneos como conseqüência dos desmatamentos constantes, aliado a uma degradação cada vez maior do solo. Mas o problema maior tem sido a salinização, cujas ações para a sua redução são: a) maiores investimentos em canais de drenagem e distribuição; b) melhor 
gerenciamento no uso da água em todas as atividades; c) fortes incentivos econômicos na conservação de água com políticas crescentes de precificação.

Desenvolvimento de estratégias nacionais para melhor gerenciamento dos dejetos animais das criações a serem implementadas a nível local; definição de medidas regulatórias e de fiscalização de padrões estabelecidos de emissão efetiva de dejetos animais, com estabelecimento de multas pesadas caso estes padrões sejam desrespeitados; disseminação de programas de gestão de resíduos dos rebanhos; instruir locais adequados para estabelecimentos de criações de rebanhos e proibir locais que não sejam propícios; aumentar o suporte à adoção e disseminação de medidas tecnológicas apropriadas, com ênfase na introdução de melhores técnicas de gerenciamento de dejetos já disponíveis em países desenvolvidos.

Como já visto o uso de insumos, em geral, produz negativos impactos no meioambiente. No entanto, o não uso destes insumos não torna, necessariamente, a agricultura sustentável. No caso da agricultura orgânica podem ocorrer problemas relacionados com erosão hídrica, e poluição de ar e água causados pelo excesso de uso de compostagem, causando emissões de amônia no ar e poluição das águas do subsolo com nitrato.

De qualquer forma, a proporção de terra usada em cultivo orgânico é ainda pequena em todo o mundo. Cabe aos governos definirem políticas de incentivo ao uso deste tipo de agricultura, principalmente em países em desenvolvimento. Neste âmbito, pode-se: adotar políticas de preços de insumos industriais que levem em conta seus custos econômicos, ou seja, incluindo as externalidades; melhor padronização, certificação e rótulos para os produtos orgânicos; estabelecimento de um procedimento de certificação internacional; maior assistência governamental aos produtores que queiram mudar da agricultura convencional para a orgânica; propiciar a capacidade de criação de sistemas de serviços de extensão, criação de associações e cooperativas; e aumentar a pesquisa no desenvolvimento de maior abrangência nas técnicas de produção orgânica.

\section{REFERÊNCIAS}

ASMAN, A. 1994. Emission and deposition of ammonia and ammonium. Nova Acta Leopold, 70: 263-297.

BOUWMAN, A. 2001. Global estimates of gaseous emissions from agricultural land. Rome, FAO. 
BOUWMAN, A., LEE, D., ASMAN, A., DENTENER, F., VAN DER HOEK, K. \& OLIVIER, J. 1997. Global high-resolution emission inventory for ammonia. Global Biogeochemical Cycles, 11(4): 561-587.

DME. 1999. The Bichel report. Copenhagen, Danish Ministry of the Environment.

GALLOWAY, J. 1995. Acid deposition: perspectives in time and space. Water, Air, Soil Pollution. 85: 15-24.

GLEICK, P. 1994. Water and conflict in the Middle East. Environment, 36(3).

GOULDING, K. 2000. Nitrate leaching from arable and horticultural land. Soil use and management, 16: 145-151.

IPCC. 2001a. Climate change 2001: synthesis report, by R. Watson \& the Core Writing Team, eds. Cambridge, UK, Cambridge University Press.

LASSEY, K., LOWE, D. \& MANNING, M. 2000. The trend in atmospheric methane and implications for isotopic constraints on the global methane budget. Global Biogeochemical Cycles, 14: 41-49.

LAVOREL, S., LAMBIN, E., FLANNIGAN, M. \& SCHOLES, M. 2001. Fires in the earth system: the need for integrated research. Global Change Newsletter, 48: 7-10.

MAREIDA, M. \& PINGALI, P. 2001. Environmental impacts of productivity enhancing crop research: a critical review. Doc. No. SDR/TAC:IAR/01/14 presented to the MidTerm Meeting, 21-25 May, Durban, South Africa.

MORROD, R. 1995. The role of pest management techniques in meeting future food needs: improved conventional inputs. Paper presented at the IFPRI Workshop on Pest Management, Food Security and the Environment: the Future to 2020. May. Washington, DC.

MOSIER, A. \& KROEZE, C. 1998. A new approach to estimate emissions of nitrous oxide from agriculture and its implications for the global change N2O budget. IGBP Global Change Newsletter, 34 (June): 8-13.

MOSIER, A., DUXBURY, J., FRENEY, J., HEINEMEYER, O. \& MINAMI, K. 1996. Nitrous oxide emissions from agricultural fields: assessment, measurement and mitigation. Plant and Soil, 181: 95-108.

MURGAI, R., ALI, M. \& BYERLEE, D. 2001. Productivity growth and sustainability in post-green revolution agriculture: the case of the Indian and Pakistan Punjabs. World Bank Research Observer, 16(2). Washington, DC.

NELSON, M. \& MAREIDA, M. 2001. Environmental impacts of the CGIAR: an assessment. Doc. No. SDR/TAC:IAR/01/11 presented to the Mid-Term Meeting, 21-25 May, Durban, South Africa.

OECD. 2001a. OECD environmental outlook to 2020. Paris, OECD.

OLDEMAN, L., HAKKELING, R. \& SOMBROEK, W. 1991. World map of the status of human-induced soil degradation, second revised ed. Wageningen, the Netherlands, ISRIC and Nairobi, UNEP.

PITCAIRN, C., LEITH, I., SHEPPARD, L., SUTTON, M., FOWLER, D., MUNRO, R., TANG, S. \& WILSON, D. 1998. The relationship between nitrogen deposition, species composition and foliar nitrogen concentrations in woodland flora in the vicinity of livestock farms. Environmental Pollution, 102: 41-50. 
PRETTY, J., BRETT, C, GEE, D, HINE, R., MASON, C., MORISON, J., RAVEN, H., RAYMENT G., VAN DER BIJL G. \& DOBBS, T. 2001. Policy challenges and priorities for internalising the externalities of modern agriculture. J. Environmental Planning and Management, 44(2): 263-283.

THOMAS, M. 1998. Ecological approaches and the development of truly integrated pest management. Paper presented to the NAS Colloquium "Plants and populations: is there time?"

UMALI, D. 1993. Irrigation induced salinity: a growing problem for development and the environment. Washington, DC, World Bank.

WANG, B., NEUE, H. \& SAMONTE, H. 1997. Effect of cultivar difference on methane emissions. Agriculture, ecosystems and environment, 62: 31-40.

WASSMANN, R., MOYA, T. \& LANTIN, R. 1998. Rice and the global environment. In Nutrient use efficiency in rice cropping systems. Special Issue of Field Crops Research: $56(1-2)$.

YUDELMAN, M., RATTA, A. \& NYGAARD, D. 1998. Pest management and food production: looking to the future. Food, Agriculture and the Environment Discussion Paper No. 25. Washington, DC, IFPRI.

ZHANG, W., TIAN, Z., ZHANG, N. \& LI, Z. 1996. Nitrate pollution of groundwater in northern China. Agriculture, Ecosystems and Environment, 59: 223-231. 